\title{
WERE AQUEOUS RIPPLES ON MARS FORMED BY FLOWING BRINES?
}

\author{
MICHAEL P. LAMB, JOHN P. GROTZINGER \\ Department of Geological and Planetary Sciences, California Institute of Technology, \\ Pasadena, California 91125 USA \\ e-mail:mpl@gps.caltech.edu \\ JOHN B. SOUTHARD \\ Department of Earth, Atmospheric, and Planetary Sciences, Massachusetts Institute of Technology, \\ Cambridge, Massachusetts 02139 USA \\ AND \\ NICHOLAS J. TOSCA \\ Department of Earth Sciences, University of Cambridge, Cambridge CB2 $3 E Q U K$
}

\begin{abstract}
The discovery in 2004 by Mars exploration rover Opportunity of sedimentary rocks with centimeter-scale trough cross-bedding is one of the compelling lines of evidence for flowing water on the Martian surface. The rocks contain a significant evaporite component mixed with weathered mafic silicates, suggesting that the aqueous fluid in contact with the sediments must have been of very high ionic strength because dissolution features are not observed. Recent thermodynamic modeling indicates that these brines could have had higher densities (by up to a factor of 1.3) and significantly higher viscosities (by up to a factor of 40) than pure water. Because fluid density and viscosity can significantly affect sediment transport mechanics, herein we analyze whether ripples could have been stable bed forms under flowing Martian brines. To this end, we compiled bed form stability diagrams with an emphasis on those studies that have considered high-viscosity fluids. For the case of viscous Martian brines, we find that ripples are stable under modest Shields numbers and low particle Reynolds numbers. These conditions translate into sediment sizes ranging from sand to gravel, and they are substantially coarser than sediment sizes for equivalent ripple-forming flows in freshwater. It is likely that ripples might also form in silt sizes under viscous brines, but these conditions (i.e., particle Reynolds numbers $<0.1$ ) have not yet been explored in flume experiments, motivating future work. Using flow-resistance equations and assuming steady uniform flow, we calculate that Marian brines must have had flow depths ranging from 0.01 to $1 \mathrm{~m}$ and flow velocities of 0.01 to $1 \mathrm{~m} / \mathrm{s}$, and been driven by gravity on slopes of $10^{-4}$ to $10^{-2}$ in order to generate the bed stresses necessary to produce ripples. These conditions seem reasonable given the interdune environment that has been proposed for the Burns formation. In addition to the potential for ripples in much coarser sediments, ripples formed by viscous brines also might be larger in height and wavelength than their freshwater counterparts by as much as a factor of 12 . Thus, large $(>10 \mathrm{~cm}$ heights) and fine-grained $(<1 \mathrm{~mm}$ particle diameter) cross strata would be compelling physical evidence for flowing brines in the Martian past, provided that independent evidence could be provided for a subaqueous (i.e., not eolian) origin of the cross-stratification. Smaller centimeter-scale ripples can also be formed by brines due to flow-depth limitations or lower-viscosity fluids, and therefore the physical sedimentological evidence in support of brines versus freshwater flows may be ambiguous in these cases.
\end{abstract}

KEY wORDs: Mars, brines, ripples, high viscosity, bed forms

\section{INTRODUCTION}

The 2004 discovery of outcropping sedimentary bedrock formed and altered in the presence of water by the Mars exploration rover Opportunity opened a new chapter in the field of sedimentary geology (Squyres et al. 2004). The investigation of these deposits, informally known as the Burns formation, demonstrated that basic stratigraphic and sedimentologic tools that have been used to evaluate the geological history of Earth may be applied to Mars with surprising rigor. For the first time on Mars, it was possible to make observations of grain-scale textures and bed-scale sedimentary structures, and to place these within a stratigraphic framework defined by distinct facies and significant surfaces (Grotzinger et al. 2005). Furthermore, it was possible to evaluate diagenetic overprints that included evidence for recrystallization, precipitation, and later dissolution of displacive evaporite minerals, and the precipitation of concretions (McLennan et al. 2005). Initial observations and interpretations were built on analysis of Eagle and Endurance craters; subsequent analysis of Erebus (Grotzinger et al. 2006, Metz et al. 2009) and Victoria craters (Squyres et al. 2009, Hayes et al. 2011, Edgar et al. this volume) supported the general applicability of the model and its relevance in the broader interpretation of Martian environmental history (McLennan and Grotzinger 2008).

A major discovery was that the Burns formation is composed of sandstone formed of composite grains that have a significant evaporite component mixed with weathered mafic silicates. The evaporitic component in these grains makes up at least $50 \%$ of the rock by weight (Clark et al. 2005) and is considered to have been in equilibrium with coeval groundwater, which necessarily must have been of very high ionic strength (McLennan et al. 2005). This would have been required to avoid pervasive leaching of the bedrock by undersaturated fluids, which might have formed large, irregular-shaped vugs, caverns, or collapse features, all of which are unobserved in the Burns formation (McLennann et al. 2005). Given the extremely high calculated solubility of the $\mathrm{Mg}, \mathrm{Fe}, \mathrm{Al}$, and $\mathrm{Ca}$ sulfate salts that are inferred to constitute the Burns formation (Tosca et al. 2005), it is highly unlikely that freshwater interacted with these rocks.

The required brines have such high ionic strength that their physical properties are calculated to be substantially different from freshwater (Tosca et al. 2011), especially their densities and viscosities. Because these properties play a fundamental role in aqueous sediment transport 
(e.g., Vanoni 1974, Southard 1991), it makes sense to ask if such brines would have been capable of generating the ripple cross-stratification preserved in the Burns formation. Previous work has considered bed form stability only under the influence of lowered Martian gravity (e.g., Komar 1979, Southard and Boguchwal 1990b, Grotzinger et al. 2005) and has not considered changes in the viscosity and density of the flow, particularly as driven by changes in brine concentration for flows of high ionic strength. Recent experiments have formed sediment fans by viscous sulfuric acid solution (Benison et al. 2008), but these were not of sufficient scale to produce ripples or cross-bedding.

The focus of this paper is to address this knowledge gap. First, we briefly review observations of the Burns formation and the centimeterscale cross-stratification within it. Second, we discuss the mechanism by which this cross-stratification was likely produced; i.e., by flowing brines of high ionic strength. Third, we compile existing bed form stability diagrams and confirm that they hold true for high-viscosity and high-density fluids. Fourth, the bed form stability diagrams for conditions of brines on Mars are translated into dimensional space to elucidate the flow depths, velocities, and grain sizes in which ripples are expected to be stable. Finally, we discuss the potential effects of high-viscosity brines on ripple size and broader implications for aqueous flows on Mars.

\section{THE BURNS FORMATION AND CENTIMETER- SCALE CROSS-STRATIFICATION}

The Burns formation is the informal name (Grotzinger et al. 2005) given to the sequence of well-sorted, moderately indurated sandstones preserved immediately beneath the surface of the Meridiani plains and examined in detail at exposures in the vicinity and within Eagle, Endurance, Erebus, and Victoria craters. Regional geology suggests that the deposit is of Late Noachian age and thus likely in excess of 3.5 Ga in age. A composite stratigraphy for Eagle and Endurance craters indicates that eolian and locally subaqueous processes deposited these sedimentary rocks as part of a "wetting-upward" dune-sand sheetinterdune depression sequence (Grotzinger et al. 2005). A composite stratigraphy for Erebus and Victoria craters demonstrates that a "drying-upward" trend followed the "wetting-upward" sequence, resulting in widespread sand dune accumulation (Metz et al. 2009, Hayes et al. 2011, Edgar et al. this volume).

The salient attributes of the depositional model for these rocks can be summarized as follows. Eolian dune facies are characterized by the occurrence of large-scale cross-bedded well-sorted sandstones (Grotzinger et al. 2005, Metz et al. 2009, Hayes et al. 2011). These sandstones have bedset thicknesses that suggest moderately large dunes in excess of several meters; eolian sand-sheet facies characterized by planar-laminated to low-angle cross-stratified, well-sorted sandstones were formed by migrating impact ripples. These facies are interpreted to represent a migrating dune system of unknown extent that was deposited under dry conditions such that the sediment was noncohesive and thus transported in migrating dune fields. Wet to evaporitic interdune facies characterized by centimeter-scale trough (or "festoon") ripple cross-lamination are diagnostic of subaqueous current transport in the lower-flow regime (Grotzinger et al. 2005). At Endurance and Eagle craters, this subaqueous facies is found in the upper part of the upper unit of the Burns formation and is interpreted to mark the location where the groundwater table breached the surface and gravity-driven aqueous currents transported the sediment. Centimeter-scale trough cross-lamination is particularly well developed at Erebus crater, where additional features suggestive of desiccation also are present (Grotzinger et al. 2006). Prism cracks are interpreted to have formed during multiple wetting and drying events, and soft-sediment deformation features are consistent with sediment liquefaction (Metz et al. 2009).

Centimeter-scale trough (or festoon) cross-stratification is observed at Eagle crater (Squyres et al. 2004, Grotzinger et al. 2005), Endurance crater (Grotzinger et al. 2005), and Erebus crater (Grotzinger et al. 2006). The best examples occur at the Overgaard and Cornville outcrops in Erebus crater (Grotzinger et al. 2006). The bedding sequence in the upper part of Overgaard contains three units: a lower cross-stratified unit, a middle planar-laminated unit, and an upper unit with centimeter-scale festoon cross-lamination (Fig. 1A). Laminae that define the middle planar-stratified unit onlap a scour surface from right to left. Note that five laminae define the middle unit on the right part of the rock (Fig. 1A, yellow bar); however, due to onlap, these decrease in number to one or two laminae at the left part of the rock. Centimeterscale cross-laminae of the upper unit scour down into the middle unit, from left to right. Note additional, stratigraphically higher, planar laminae in the middle unit at the far left (Fig. 1A, green arrows), where the scour surface rises up through the section.

Centimeter-scale trough cross-stratification in the upper unit forms a bedset with at least 3 to $4 \mathrm{~cm}$ of apparent thickness. Blue arrows point to three distinct troughs, as indicated by basal truncation and concaveupward geometry. Several superimposed sets show basal scouring and backfilling by concave-upward to occasionally convex-upward crosslaminae (Fig. 1A, red arrows). Truncation surfaces and backfilling of subjacent sets are well expressed in the left-center part of the upper unit. Individual troughs are 3 to $4 \mathrm{~cm}$ wide. A mosaic of Microscopic Imager (MI) frames was constructed to coincide with the middle and upper units of upper Overgaard; this provides additional supporting detail of the grain-scale variability in primary lamination (Fig. 1B). Furthermore, the MI mosaic was used to construct a digital elevation model (DEM) of the outcrop topography (Fig. 1C); the rock surface is flat at the relevant scale across the left-center region where the upper unit is exposed, and otherwise bedding shows no systematic relationship with respect to the minor local slopes. This demonstrates that the cross-lamination is a primary attribute of the rock rather than an artifact of erosion.

Centimeter-scale trough cross-lamination is pervasive at the Cornville outcrop, covering its entire exposure (Fig. 2). This represents a true stratigraphic thickness of close to 20 to $30 \mathrm{~cm}$ (Grotzinger et al. 2006). Centimeter-scale trough cross-lamination is well developed near the center of the rock. The geometry and scale of these cross-laminae sets are nearly indistinguishable from terrestrial analogs formed in aqueous flows (Fig. 3). Cornville festoon cross-laminae sets are up to 1 to $2 \mathrm{~cm}$ thick and up to 2 to $3 \mathrm{~cm}$ wide in sections that are most likely transverse to flow. The rock surface exposes a cut that is largely transverse to flow, with a small component of climb from right to left.

\section{RATIONALE FOR RIPPLE FORMATION BY AQUEOUS FLOWS}

When subjected to shear stresses created by shallow, freshwater flows with moderate current velocities, fine- to medium-grained sand spontaneously forms highly sinuous, crested ripples with amplitudes up to a few centimeters (Southard and Boguchwal 1973, Southard and Boguchwal 1990a). The diagnostic attribute of such ripples is exposed in cuts transverse to flow, where laminae have a trough-shaped geometry (Rubin 1987). Cross-lamination of this type and scale is not known to develop in eolian flows (see discussion in Grotzinger et al. 2005) and, to our knowledge, has not been observed in deposits resulting from other types of flows such as volcanic- or impactgenerated base surges (e.g., Fralick et al. this volume). Very likely, small-scale ripples are not stable under the conditions of high sedimentation rates and rapidly decelerating currents that are characteristic of base-surge flows. For these reasons, the presence of centimeter-scale cross-lamination in the Burns formation has been regarded as strong evidence for overland water flow across the ancient surface of Mars (Squyres et al. 2004, Grotzinger et al. 2005). 

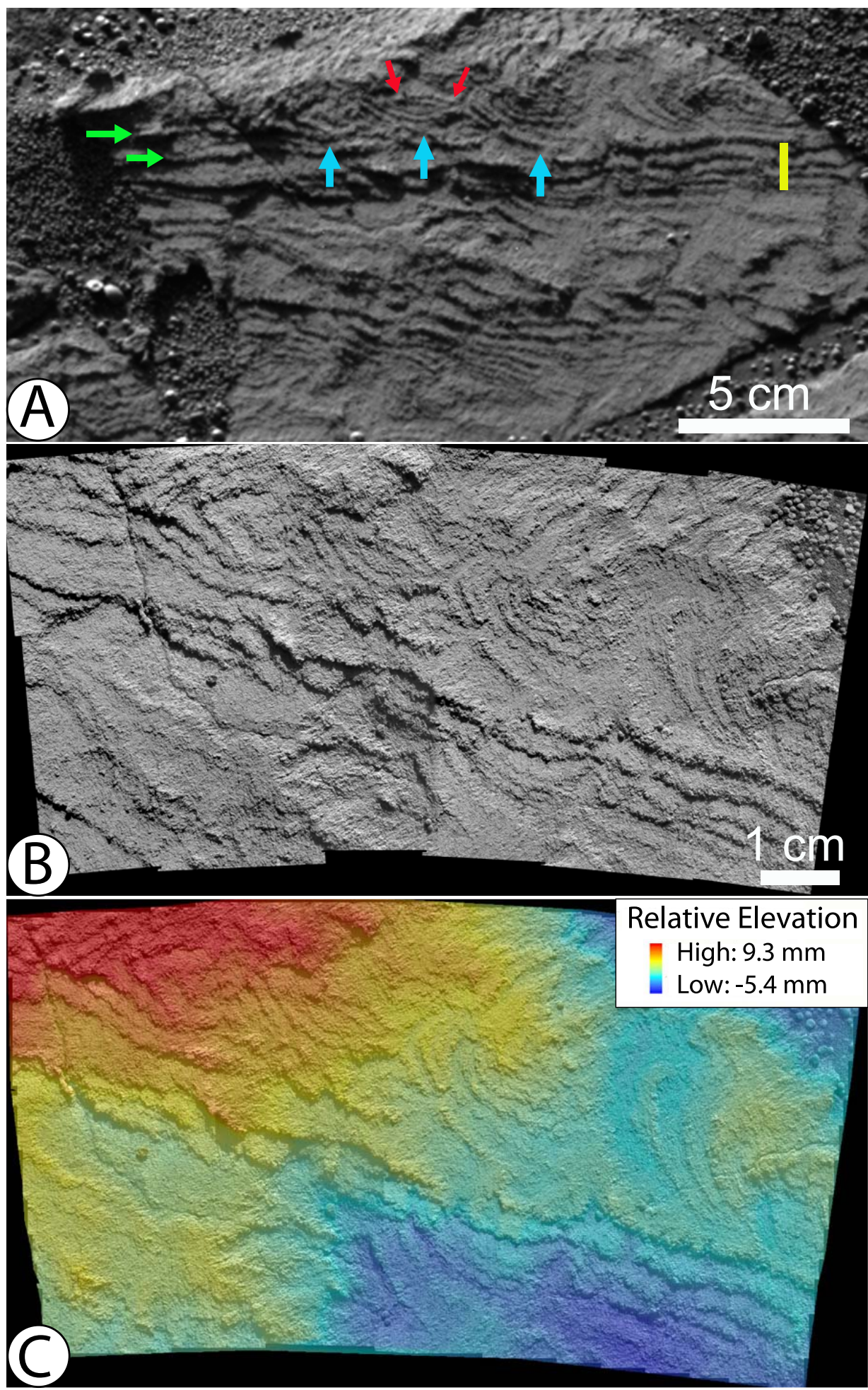

FIG. 1. Centimeter-scale trough cross-lamination at Overgaard outcrop, Burns formation, Erebus crater, Mars. A) Cross-stratified lower unit, overlain by a planar-laminated middle unit (indicated by yellow bar) and a trough cross-laminated upper unit. See text for discussion. This lowangle light image was acquired on sol 716 at 16:15:46 LTST, sequence id p2593, 432 nanometer filter. B) Microscopic Imager mosaic of the middle and upper units. Note generally granular texture and excellent sorting, right-to-left pinch-out of the middle unit, and stratal truncation and downlap of the cross-laminae in upper unit (compare with 2a, red arrows). The mosaic was constructed from images obtained on sols 721 and 723. C) Digital elevation model (DEM) of MI mosaic. Note the lack of correlation between topography and bedding in left-central part of the upper unit, indicating a primary origin of stratal (lamina) geometries. See Grotzinger et al. (2006) for further details on the image attributes and technical details on DEM construction. After Grotzinger et al. (2006). 


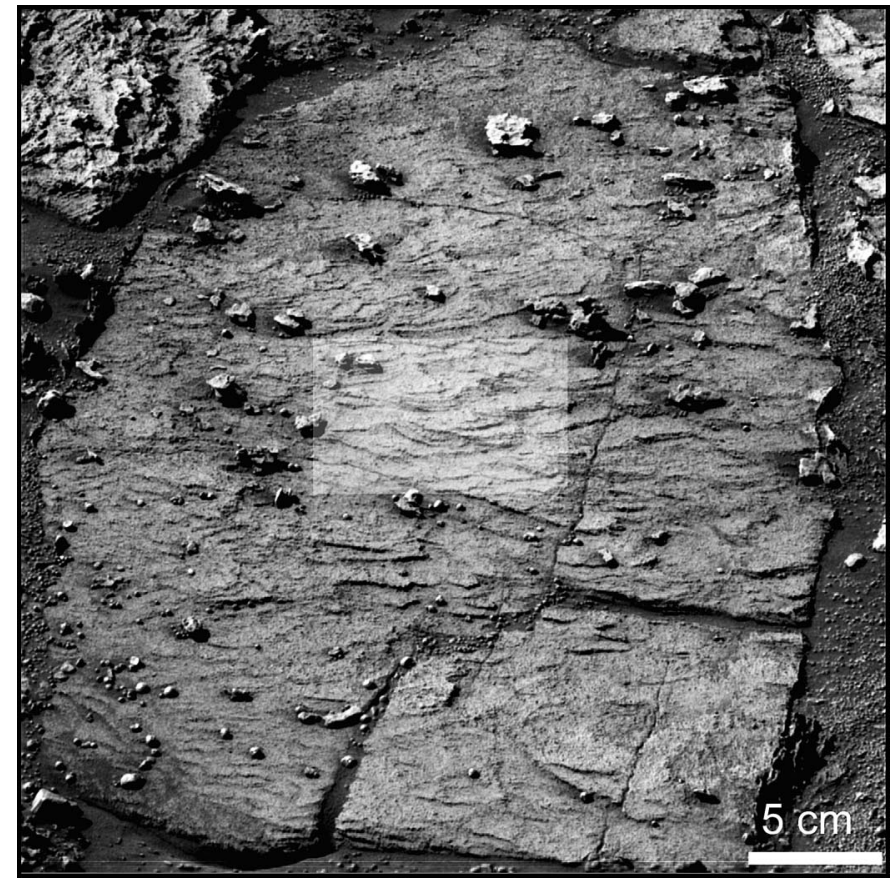

FIG. 2.-Centimeter-scale trough cross-lamination is abundant at the Cornville outcrop. The center part is highlighted and approximates the area of Figure 3A. Exposed surface is largely transverse to flow, with a small component of climb from right to left. Note abundant scour surfaces, which truncate the underlying concave-up laminae, overlain by downlapping cross-laminae of the next set. Note the moderately steep dips of laminae exposed along the left side of the crack at the center part of the lower boundary of the rock. These indicate that the true thickness of this cross-laminated unit must be less than the apparent thickness, which equals the long dimension of the rock $(\sim 50 \mathrm{~cm})$; correcting for dip $(\sim 30$ degrees $)$, the true thickness of centimeter-scale cross-lamination is likely still to be on the order of several tens of centimeters, the thickest observed at Meridiani. Superres image of Cornville acquired sol 705 at 14:15:22 LTST, using Pancam's 482 nanometer filter (sequence id p2576).

\section{RATIONALE TO INVOKE BRINES}

In addition to the diagenetic textures that place constraints on the composition of groundwater that interacted with the Burns formation (general absence of rock dissolution features), the primary textures also strongly indicate brines. Recall that the each grain is interpreted to consist of a mixture of $>50 \%$ sulfate plus altered silicate minerals (Clark et al. 2005). These minerals are so fine grained that they cannot be distinguished with the Opportunity rover's microscopic imager (MI) (McLennan et al. 2005). The grains themselves are typically sand size, 0.3 to $0.8 \mathrm{~mm}$ in diameter, yet they are composed of particles likely to be of silt size and finer. Furthermore, the minerals that compose these grains consist largely of Mg-sulfates (e.g., originally epsomite), which in concentrated Martian surface waters have very high solubility, even higher than halite (Tosca et al. 2005, 2011).

Therefore, it is conservative to assume the solubility of halite to provide a rough estimate of dissolution rates in freshwater for the sand grains of the Burns formation. In natural systems, the dissolution rates of highly soluble minerals (e.g., Mg-sulfates and halite) are frequently
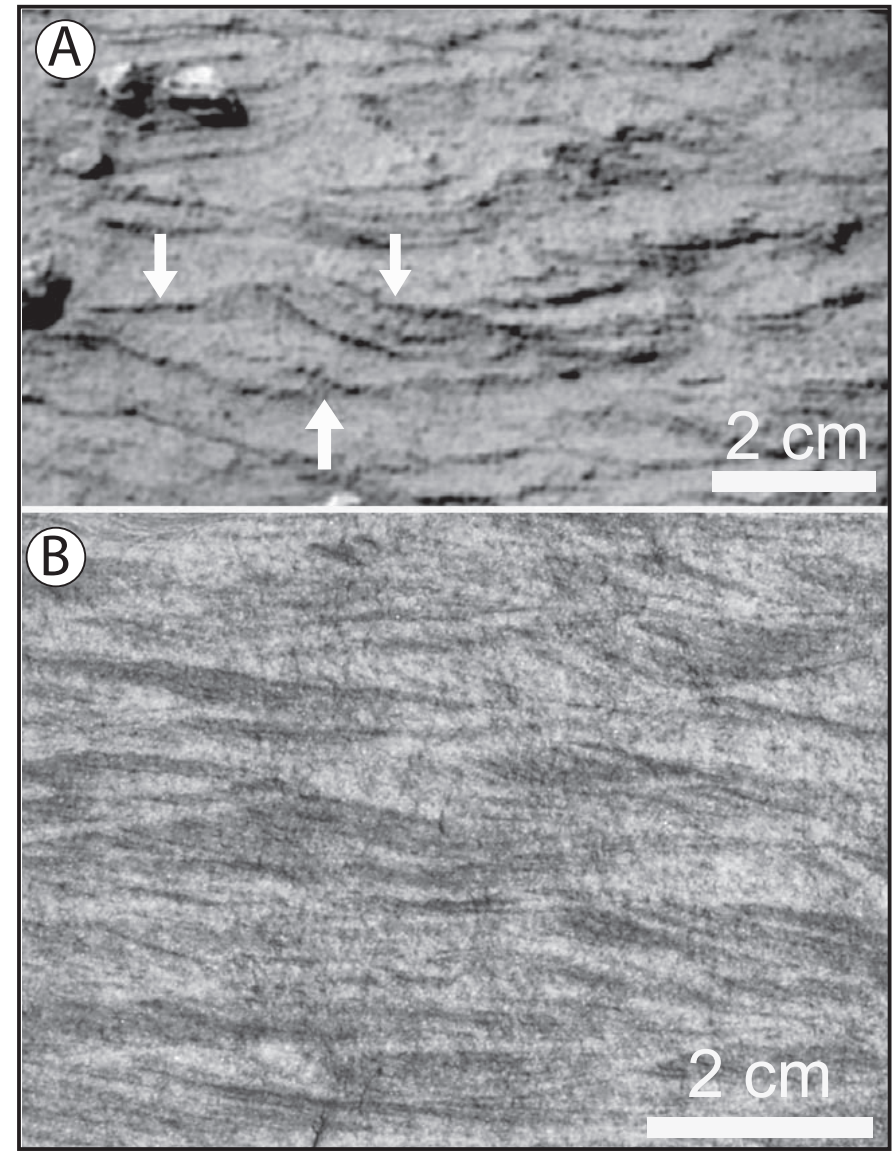

FIG. 3.-A) Enlargement of the center part of Figure 2. Welldeveloped centimeter-scale trough cross-lamination. In the leftcenter of the image, the set has a classic concave-up lower bounding surface (up arrow), and the upper boundaries are marked by two intersecting concave-up surfaces (down arrows). Internal cross-laminae are truncated by the upper bounding surface on the right, and that bounding surface is then downlapped by cross-laminae of the superjacent set. B) Terrestrial centimeterscale trough cross-lamination (Cretaceous Mesa Verde Group) shows strong geometric similarity with that preserved in Cornville. Compare with part A.

limited by the transport of dissolved components from the dissolving mineral surface (Lasaga 1998). For example, experimental work on the dissolution of sand-size halite spheres in water indicates that such grains cannot survive in fresh stagnant water for more than about 2 minutes at $20^{\circ} \mathrm{C}$ (Simon 1981, Kerr 1995, Alkattan 1997, Velbel 2004) (Fig. 4). Decreasing temperature slows the dissolution rate (Velbel 2004), but the timescale required to completely dissolve sand-size grains still would be only a few minutes at $0^{\circ} \mathrm{C}$ (Fig. 4). Temperatures much below 0 to $-3^{\circ} \mathrm{C}$ would have produced a significant amount of water ice, which is not supported as a sedimentary component (but cannot be entirely ruled out) based on outcrop observations to date. Allowing the grains to fall through freshwater greatly increases the dissolution rate, so that survival times are measured in tens of seconds rather than minutes (Velbel 2004); in the presence of fully turbulent flows, dissolution rates are even further increased (Kerr 1995). Finally, it is worth pointing out — estimations of dissolution rates aside — that it 


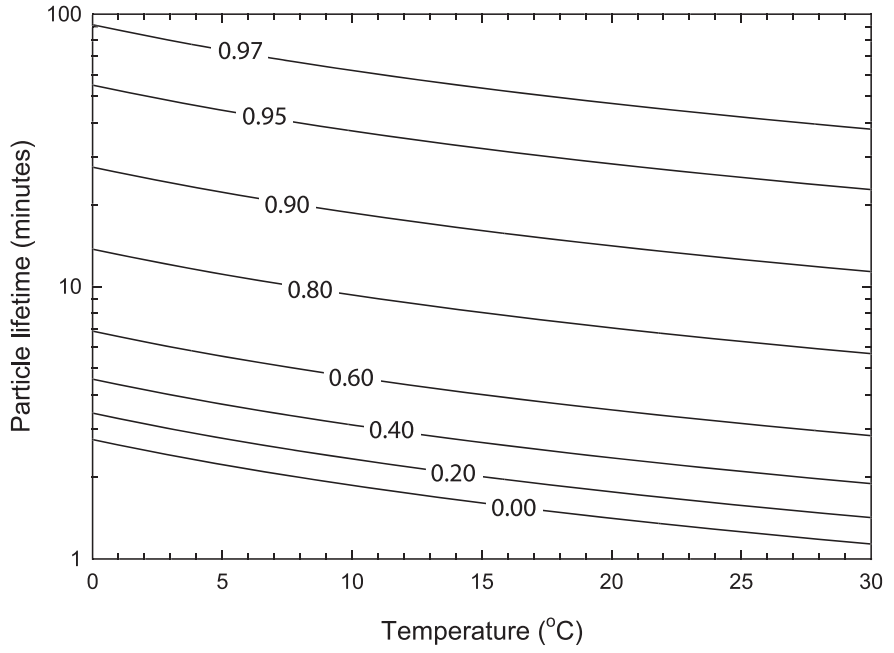

FIG. 4.- The timescale for a 1-mm-diameter particle of halite to completely dissolve as a function of temperature based on experimental data from Alkattan et al. (1997). The contours are the saturation state (i.e., concentration normalized by the equilibrium concentration), where zero represents freshwater, and unity represents a fully saturated brine. Although the dissolution timescales for magnesium sulfate, which is a better analog for Martian sediments than halite, are not as well known, the relative effects of temperature and concentration should be equivalent to halite (Lasaga 1998).

is logical to assume that groundwater migrating through a regionally extensive sulfate-rich unit should be saturated with respect to those mineral phases. Regional stratigraphy and mineralogy favor this.

The Burns formation shows multiple stacked sets of ripple crosslamination with an apparently small angle of climb over a thickness of 20 to $30 \mathrm{~cm}$, indicating ripple migration under conditions of sustained flow (Grotzinger et al. 2006). Because the timescale of ripple formation can be expected to be at least tens of minutes, if not days or longer (Southard 1991, Baas 1999, Betat et al. 2002), we need to seek other effects to explain the anomalous survival of such soluble grains.

One possible influence is given by the observation that the minor mineralogical component of the sand grains of the Burns formation is likely to be altered silicate minerals. These would have orders of magnitude lower solubility than the sulfates, and this might increase their survival in dilute flows. However, the dissolution of the sulfate component would still dramatically weaken the grain, making it much more susceptible to impact-driven disintegration.

Another possible explanation, which is the focus of the work herein, is that the aqueous ripple-forming flows were concentrated brines of high ionic strength. Dissolution modeling suggests that the brines must have been nearly saturated in order to extend particle lifetimes to tens of minutes or longer (Fig. 4). Recent thermodynamic modeling, which is based in part on thousands of laboratory measurements, suggests that brines could have existed on the Martian surface in chemical equilibrium with the host rock (Tosca et al. 2011). The modeled brines are of such high ionic strength, however, that their physical properties are substantially different than pure water (Tosca et al. 2011). In some cases, the fluid viscosity of the modeled brines is 40fold that of pure water. Given that, among other variables, fluid density and viscosity influence the stability of bed forms (Vanoni 1974, Boguchwal and Southard 1990, Southard and Boguchwal 1990b), it is important to verify whether ripples could indeed form as a result of flowing brines on Mars.

\section{DIMENSIONLESS REPRESENTATION OF BED FORM STABILITY FIELDS}

There have been several attempts to formulate a graphical framework representing the conditions of flow, sediment, and fluid for the stable existence of current ripples. In steady, uniform, openchannel flow of a Newtonian fluid, dimensional analysis indicates that at least three independent dimensionless variables are needed to describe stable bed form states (Vanoni 1974, Van Rijn 1984, Southard 1991, van den Berg and van Gelder 1993, Garcia 2007). These dimensionless variables provide a set of scale-modeling parameters that can take into account a wide range of sedimentologically interesting behaviors, such as the effects of changing grain size, current velocity, flow depth, fluid viscosity, grain density, and the acceleration of gravity. The dimensionless numbers are nonunique, however; dimensional analysis indicates that there are many equally valid sets of three nondimensional variables. For example, Boguchwal and Southard (1990) prefer to express their experimental bed form stability results in terms of a dimensionless flow depth, dimensionless flow velocity, and a dimensionless particle size. Herein, we choose another common and equally valid approach to describe bed states by representing the flow strength (or intensity of sediment transport) through the dimensionless Shields parameter,

$$
\tau_{*}=\frac{\tau_{\mathrm{b}}}{\left(\rho_{\mathrm{s}}-\rho\right) g D}
$$

where $\tau_{\mathrm{b}}$ is the shear stress at the bed, $\rho_{\mathrm{s}}$ is the density of sediment, $\rho$ is the fluid density, $g$ is the acceleration due to gravity, and $D$ is the particle diameter. The effective sediment size is accounted for using a particle Reynolds number,

$$
\operatorname{Re}_{p}=\frac{(\operatorname{Rg} D)^{1 / 2} D}{v}
$$

where $R=\left(\rho_{\mathrm{s}}-\rho\right) / \rho$ is the submerged specific density of sediment, and $v$ is the kinematic viscosity of the fluid (e.g., Garcia 2007). The final dimensionless number needed to describe bed form stability in this framework is a dimensionless flow depth, which, by assuming that $R$ and a bed friction coefficient are constant (e.g., Garcia 2007), is often written as a Froude number,

$$
\operatorname{Fr}=U / \sqrt{g h}
$$

where $U$ is the mean flow velocity, and $h$ is the flow depth. Numerous flume experiments have shown this to be a tractable strategy. For Fr greater than about unity, flows are considered supercritical, and antidunes form rather than ripples or dunes (Vanoni 1974, Van Rijn 1984, Southard and Boguchwal 1990a). For Fr $<1$, bed form stability is independent of $\mathrm{Fr}$, and therefore it can be neglected as a variable. Thus, Eq. 1 and Eq. 2 alone are sufficient to elucidate the stability of ripple bed forms for the subcritical flows of concern here (e.g., van den Berg and van Gelder 1993).

We compiled results from five sediment-transport and bed form studies to build a comprehensive bed form stability diagram that spans a larger range in $\operatorname{Re}_{p}$ than any of the individual studies alone (Fig. 5). Each study contains many data points (in some cases, hundreds) that each represent a single flume experiment or field observation, and these are not repeated here. Instead, we show the dividing lines that were empirically found to bound the bed form stability fields from each study. The compilation includes a lower boundary separating no motion from the fields of sediment transport; i.e., the Shields curve (Shields 1936). For coarse particle sizes, we represent the Shields curve 


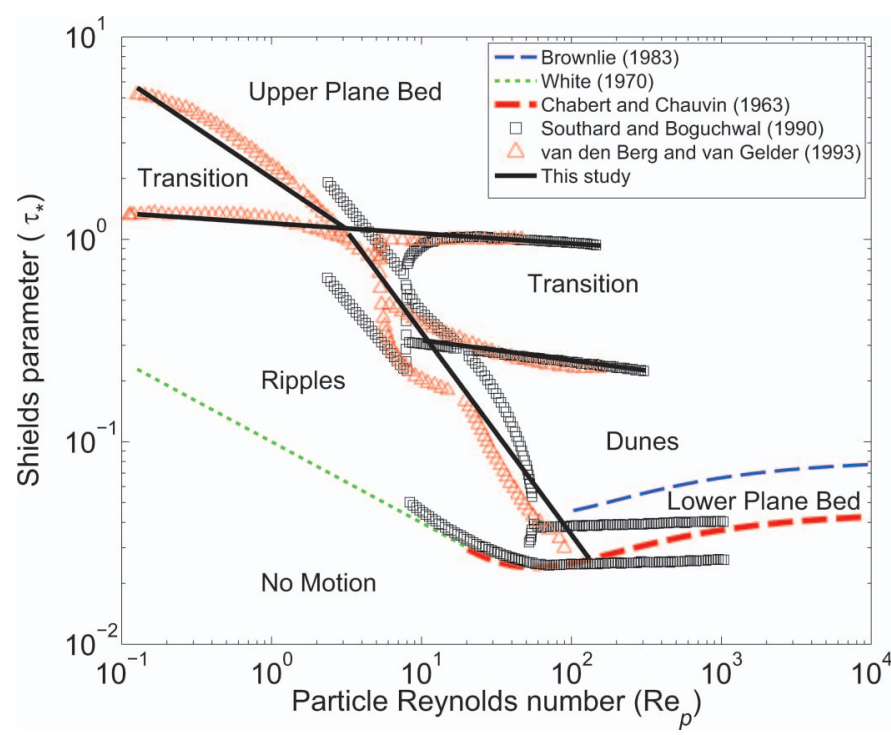

FIG. 5.-Phases of bed form stability as a function of Shields parameter and particle Reynolds number. Summary boundaries from five different studies are shown, separating no motion from lower plane bed, ripples, dunes, and upper plane bed. Results from previous studies were given in terms of $\tau_{*}$ and $\mathrm{Re}_{p}$, except the study of Southard and Boguchwal (1990a), from which we translated their Figure 11 into the present coordinate system. The solid black line represents our power-law fits (by eye).

following the semi-empirical fit to incipient motion data of Parker (1991) and Brownlie (1983). For small $\mathrm{Re}_{p}$, we use our own fit to the experimental data of White (1970) because he used a high-viscosity fluid $\left(v=8 \times 10^{-6} \mathrm{~m}^{2} / \mathrm{s}\right.$, approximately eightfold that of freshwater on Earth's surface) to achieve small $\mathrm{Re}_{p}$, rather than the more common approach of reducing $D$, which avoids the complicating cohesive effects common to clay-size sediment. In the regimes of mobile sediment, ripples form at low $\operatorname{Re}_{p}$ and moderate values of $\tau_{*}$, and ripples wash out to the upper plane bed at $\tau_{*}$ greater than approximately unity. For large $\mathrm{Re}_{p}$, there exists a stable regime of lower plane bed, followed by dunes and upper plane bed with increasing Shields parameter. Ripples are similar to dunes but are usually smaller and form in the presence of a viscous sublayer (i.e., small $\mathrm{Re}_{p}$ ) (e.g., Garcia 2007). For these bed form stability transitions, we show the results of Chabert and Chauvin (1963), as well as the comprehensive studies of Southard and Boguchwal (1990a) and van den Berg and van Gelder (1993). For the case of Southard and Boguchwal, we recast their dimensional diagram (their Fig. 11) into the dimensionless variables given by Eq. 1 and Eq. 2 .

It is encouraging to note that the stability field boundaries are relatively consistent despite the fact that the databases contain both field and flume data, measurements were made by different workers, and data span a wide range of flow velocities, flow depths, particle sizes, particle densities, fluid densities, and fluid viscosities (Fig. 5). This illustrates the robustness of the dimensionless framework.

In order to explore bed form stability for Martian brines, we need a summary bed form stability diagram that can be translated into dimensional space. To accomplish this, and given the ambiguity of some of the transitions from the different studies in Figure 5, we fit power-law boundaries (by eye) to the bed form stability transitions (Fig. 5). The resulting compilation shows solid lines where the stability fields have been explored either experimentally or with field data, and

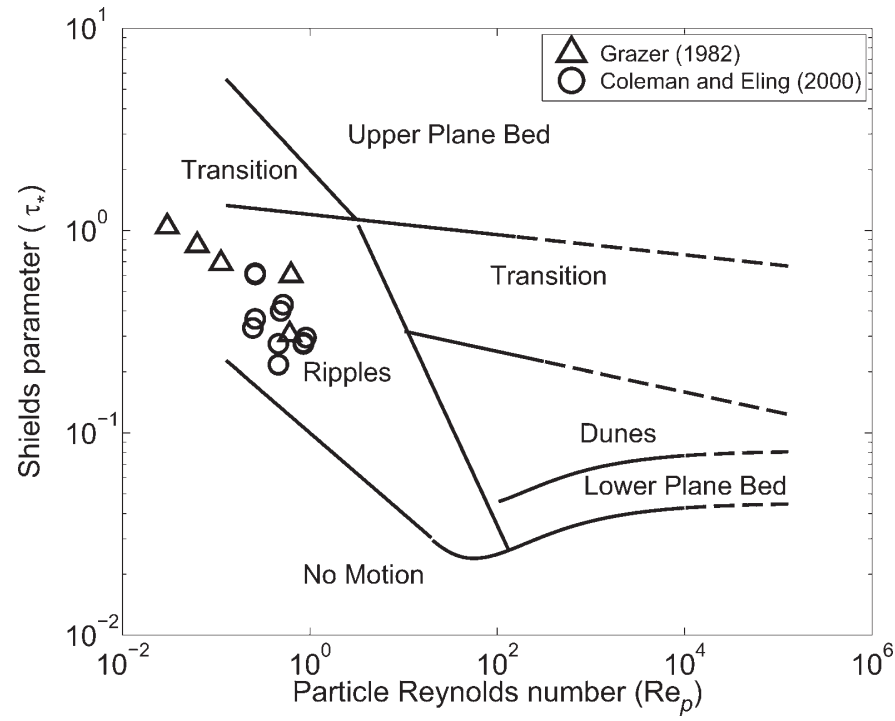

FIG. 6.- Summary bed form stability diagram. The solid lines are fits to the bed form transition boundaries as shown in Figure 5. The dashed lines are extrapolations of these boundaries to higher particle Reynolds numbers. Also shown are data points from two studies that produced ripples in a series of experiments with highviscosity fluids.

dashed lines represent power-law extrapolations (Fig. 6). Thus, the parameter space for $\operatorname{Re}_{p}<10^{-1}$, for example, has yet to be explored experimentally. The reason for this is that, for freshwater flows typical of Earth-surface conditions, $\mathrm{Re}_{p}<10^{-1}$ corresponds to clay-size particles, for which cohesive effects become important and bed form stability can no longer be described completely by Eq. 1 and Eq. 2 (e.g., Dzulynski and Sanders 1962, Grazer 1982, Mehta 1991, Best and Leeder 1993). For Martian brines, however, small values of $\mathrm{Re}_{p}$ are expected for coarser, noncohesive particles owing to the inverse dependence of $\operatorname{Re}_{p}$ on viscosity (Eq. 2).

For most experiments and field observations, $\operatorname{Re}_{p}$ has been varied through varying the particle size (Eq. 2), which is a practical and relevant strategy for most natural flows on Earth. However, we are concerned instead with variations in $\operatorname{Re}_{p}$ through the kinematic viscosity, so it is important to verify that the dimensionless framework holds true under varying viscosity. This was precisely the objective of the experimental study of Boguchwal and Southard (1990) and Southard and Boguchwal (1990b), which explored bed form stability under water flows with temperatures ranging from 10 to $75^{\circ} \mathrm{C}$, corresponding to viscosities that span $3.7 \times 10^{-7}$ to $1.4 \times 10^{-6} \mathrm{~m}^{2} / \mathrm{s}$. They found the dimensionless framework to hold true, and their data were used in part to construct the boundaries of Southard and Boguchwal (1990a) (Fig. 5). Less work exists on sediment transport under high-viscosity fluids, but two studies are of note. Grazer (1982) produced ripples on a silt bed at very low $\operatorname{Re}_{p}$ using water-sucrose solutions with viscosities as high as $1.05 \times 10^{-5} \mathrm{~m}^{2} / \mathrm{s}$, which approach the highest viscosity condition modeled by Tosca et al. (2011) of $v=4$ $\times 10^{-5} \mathrm{~m}^{2} / \mathrm{s}$ for Martian brines. More recently, Coleman and Eling (2000) produced ripples in eleven different experiments on a sand bed using hydraulic oil with a viscosity as high as $v=9 \times 10^{-5} \mathrm{~m}^{2} / \mathrm{s}$; i.e., twice that inferred for the most viscous case on Mars. The viscosity was so great in the experiments of Coleman and Eling that the flows were laminar. We recast the data presented in these studies to calculate $\tau_{*}$ and $\operatorname{Re}_{p}$ following Eq. 1 and Eq. 2 (Fig. 6). The resulting data points 


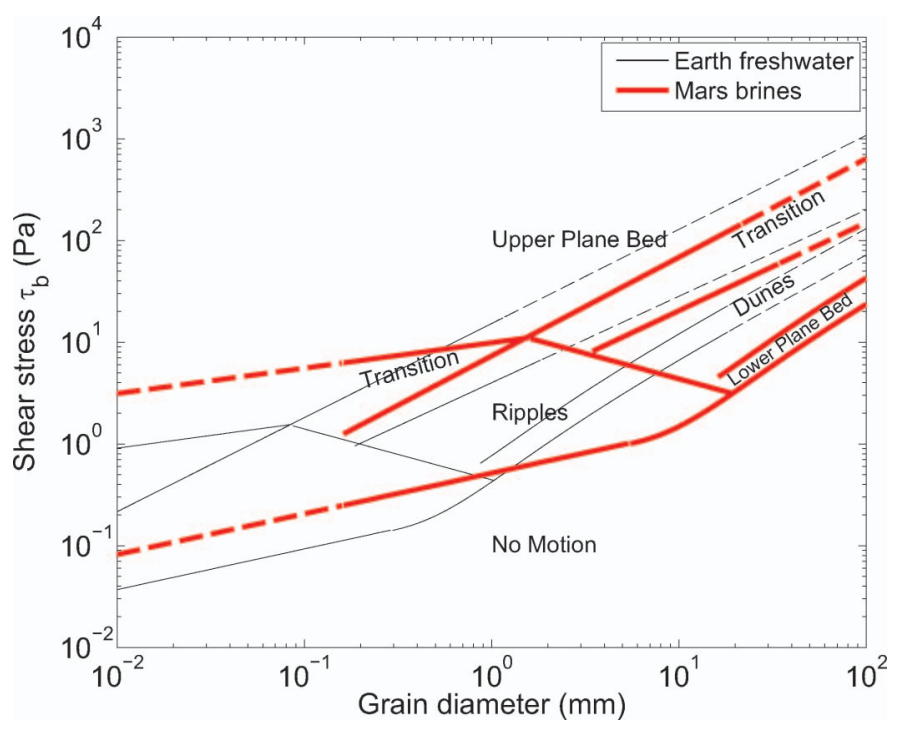

FIG. 7.-Translation of Figure 6 into dimensional space for the case of freshwater flows on Earth and a dense, viscous brine on Mars. See text for specific fluid properties. Note the dramatic shift in bed form space to coarser sediment for the brine case. Solid lines represent boundaries that have been explored experimentally following Figures 5 and 6, and dashed lines are extrapolations. Labels correspond to the Martian case.

plot within the ripple stability field, confirming that the dimensionless framework is capturing the appropriate physics, regardless of the particle size or the fluid viscosity.

\section{FLOW CONDITIONS FOR RIPPLE FORMATION BY MARTIAN BRINES}

Equations 1 and 2 reveal that ripple formation depends on fluid density, viscosity, and gravity, all of which are different for brines on Mars compared to freshwater flows on Earth. To illustrate this effect, we can replot the stability fields of Figure 6 in terms of the flow stress on the bed $\left(\tau_{\mathrm{b}}\right)$ versus particle diameter $(D)$. To accomplish this, estimates are needed for the physical properties of the brines as well as the density of sediment and acceleration due to gravity. Work by Tosca et al. (2011) indicates that Martian brines might have had viscosities as high as $v=4 \times 10^{-5} \mathrm{~m}^{2} / \mathrm{s}$ and densities as high as $\rho=1300 \mathrm{~kg} / \mathrm{m}^{3}$. Herein, these upper estimates are used to analyze the possible existence of ripples. We assume particle densities of $\rho_{\mathrm{s}}=2650 \mathrm{~kg} / \mathrm{m}^{3}$, which seems reasonable given that evaporite minerals range from 1900 to $2400 \mathrm{~kg} / \mathrm{m}^{3}$ and there is potential for a mixture of basaltic grains (3000 $\mathrm{kg} / \mathrm{m}^{3}$ ), and set $g=3.73 \mathrm{~m} / \mathrm{s}^{2}$. A reference case for freshwater flows transporting siliceous material on Earth is also shown where $\rho=1000$ $\mathrm{kg} / \mathrm{m}^{3}, \rho_{\mathrm{s}}=2650 \mathrm{~kg} / \mathrm{m}^{3}, v=10^{-6} \mathrm{~m}^{2} / \mathrm{s}$, and $g=9.81 \mathrm{~m} / \mathrm{s}^{2}$.

There is a significant shift in bed form stability for the Martian brines as compared to freshwater flows on Earth (Fig. 7). This is primarily due to the 40 -fold increase in fluid viscosity. For example, in comparison to freshwater on Earth, finer-grained sediment $(D<2$ $\mathrm{mm}$ ) moves at higher stresses by flowing Martian brines. In contrast, gravel sizes and larger $(D>2 \mathrm{~mm})$ move at lower stresses for Martian brines than freshwater on Earth. This is because of the strong particle Reynolds number dependence of incipient motion for fine sediment. Heightened viscosity increases the size of the viscous sublayer near the bed and decreases the local velocities about grains for a given bed shear stress. Coarse particles, on the other hand, protrude above the viscous sublayer (i.e., hydraulically transitional or rough flow) and are less sensitive to the particle Reynolds number and viscosity (Yalin 1977).

Ripples on Earth are stable in freshwater for particles in the silt and sand size ranges, with an upper maximum size of about $D=1 \mathrm{~mm}$ (Fig. 7). In contrast, ripples formed by Martian brines are predicted to form in much coarser particle sizes, ranging from sand to coarse gravel, up to $D \approx 20 \mathrm{~mm}$. Unlike freshwater flows on Earth, where dunes are common in sand, under conditions of viscous Martian brines, dunes are predicted to form only in gravel sizes and coarser $(D>2 \mathrm{~mm})$. It is likely that ripples form under Martian brines for silt-size grains as well, but the particle Reynolds number regime corresponding to $D<0.2$ $\mathrm{mm}$ for Martian brines has yet to be explored experimentally (Fig. 7). Thus, ripples have the potential to be a stable bed form over a wide range of particle sizes when formed under viscous brines, including sand, gravel, and potentially silt. However, in order for ripples to form, the flows must generate the necessary bed stresses of $\sim 0.1$ to $10 \mathrm{~Pa}$.

To investigate the flow dynamics that could result in the necessary bed stresses to generate ripples, we assume steady and uniform flow and calculate the depth-averaged flow velocity, $U$, from

$$
\begin{aligned}
& U=\frac{u_{*}^{2} h}{3 v}, \quad \text { for } \operatorname{Re}<5 \times 10^{2}, \\
& U=\frac{1}{h} \int_{z_{0}}^{h} \frac{u *}{\kappa} \ln \left(\frac{z}{z_{0}}\right) d z, \quad \text { for } \operatorname{Re}>10^{3},
\end{aligned}
$$

where $u_{*} \equiv \sqrt{\tau_{b} / \rho}$ is the bed shear velocity, $\kappa$ is von Kármán's constant (0.4), $z$ is the height above the bed, $z_{0}$ is the bed roughness length scale, and $\mathrm{Re}=U h / v$ is the flow Reynolds number, which determines whether the flow is laminar (Eq. 4A) or turbulent (Eq. 4B) (e.g., Chow 1959). For turbulent flow, we set the roughness length scale equal to

$$
\begin{aligned}
& z_{0}=v /\left(9 u_{*}\right), \text { for } \operatorname{Re}_{\mathrm{p}}<5, \\
& z_{0}=D / 10, \quad \text { for } \operatorname{Re}_{\mathrm{p}}>100,
\end{aligned}
$$

corresponding to hydraulically smooth (Eq. 5A) and hydraulically rough (Eq. 5B) basal boundary conditions (e.g., Yalin 1977).

The resulting calculations are shown in Figure 8 for $D=0.5 \mathrm{~mm}$ size sediment and for the most viscous brine modeled by Tosca et al. (2011) (i.e., $\rho=1300 \mathrm{~kg} / \mathrm{m}^{3}, v=4 \times 10^{-5} \mathrm{~m}^{2} / \mathrm{s}$ ). Note, for transitionally turbulent $\left(5 \times 10^{2}<\operatorname{Re}<10^{3}\right)$ or transitionally rough $\left(5<\operatorname{Re}_{\mathrm{p}}<10^{2}\right)$ flow, we matched the end-member solutions by eye for simplicity. Also shown is the boundary for supercritical flow $(\mathrm{Fr}=1)$, which is approximately where ripples should give way to antidunes. As predicted from Figure 7, ripples are stable for basal shear stresses ranging from 0.1 to $10 \mathrm{~Pa}$. This corresponds to flow velocities of 0.01 to $1 \mathrm{~m} / \mathrm{s}$ and flow depths in the range of 0.01 to $1 \mathrm{~m}$. For freshwater flows on Earth, ripples in sand are almost always formed under turbulent flows. In contrast, the predicted properties of Martian brines are so viscous that ripples are predicted to form under a wide range of laminar and transitionally turbulent flows, consistent with recent experimental and theoretical findings (e.g., Coleman and Eling 2000, Devauchelle et al. 2010, Lajeunesse et al. 2010).

For a given flow depth, there is a unique value of bed slope $(S=\sin \theta$, where $\theta$ is the bed-slope angle from horizontal) that is needed to generate the appropriate bed stresses to form ripples, assuming steady and uniform flow (i.e., $\tau_{\mathrm{b}}=\rho g h S$ ) (Fig. 8). The resulting values of slope of $10^{-4}<S<10^{-2}$ seem reasonable for the interdune environment interpreted by Grotzinger et al. (2005) for the Burns formation. Nonuniform flow is also possible, for example, if brines flowed from one interdune into an adjacent depression.

By the line of reasoning presented above, we conclude that ripples 


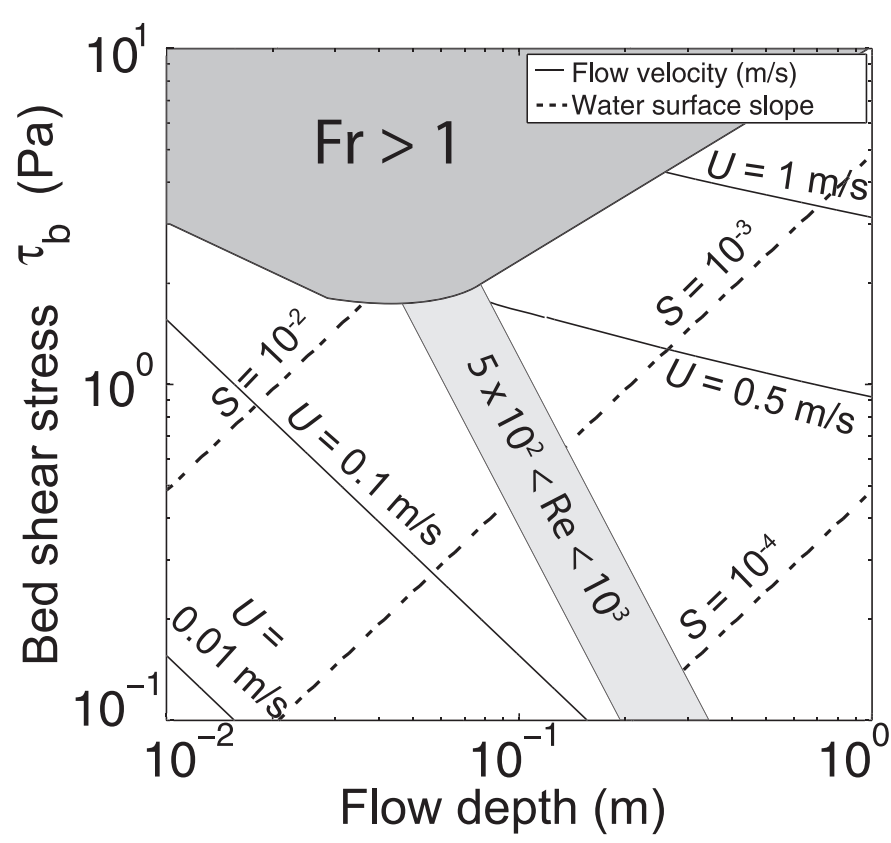

FIG. 8.-Combinations of depth-averaged flow velocity and depth necessary to generate ripples by flowing brines on Mars. The bed shear stress needed to generate ripples ranges from approximately $10^{-1}$ to $10 \mathrm{~Pa}$ (Fig. 7). Assuming steady and uniform flow, the flow velocity $(U)$ and depth combinations have a unique value of bed slope gradient $(S)$, which is also shown. Ripples are not expected to form where $\mathrm{Fr}>1$ due to standing waves that generate antidunes. The zone of transitionally turbulent flow (i.e., $5 \times 10^{2}<\operatorname{Re}<10^{3}$ ) is also shown, with laminar flow occurring for smaller flow depths and velocities and turbulent flow occurring for larger flow depths and velocities.

should be stable over a wide range of particle sizes and bed shear stresses, even for the most viscous brine considered by Tosca et al. (2011). In fact, ripples are expected to be stable over a much larger range in conditions under Martian brines, as compared to freshwater flows on Earth, including most of the gravel size range. Moreover, viscous brines are predicted to be capable of generating the bed stresses necessary to generate flows under reasonable flow conditions, including centimeter- to decimeter-scale flow depths, velocities of centimeters per second, and modest bed slopes. However, the flow conditions for ripple formation in sand sizes by viscous, dense brines have not yet been explored experimentally. This motivates the need for experiments on bed form stability for $\operatorname{Re}_{p}<10^{-1}$.

\section{EFFECT OF BRINE VISCOSITY ON RIPPLE SIZE}

It is distinctive of current ripples that for flows of a given fluid, like water at room temperature, the size of current ripples (average spacing or average height) varies by less than a factor of three or so over the entire range of sediment sizes for which ripples are the stable bed configuration. For example, in freshwater flows ripple heights $\left(\eta_{f}\right)$ and wavelengths $\left(\lambda_{\mathrm{f}}\right)$ are typically about $\eta_{\mathrm{f}}=1.5 \mathrm{~cm}$ and $\lambda_{\mathrm{f}}=9 \mathrm{~cm}$ (e.g., Southard 1991). The same is not true, however, for the kinematic viscosity of the fluid. Dimensional analysis indicates that the kinematic viscosity $v$ enters any given dimensionless length variable to the inverse two-thirds power (Southard and Boguchwal 1990a). Thus, dynamically similar-sized ripples in a viscous brine would have heights of $\eta_{b}=\left(v_{b} / v_{f}\right)^{2 / 3} \eta_{f}$ and wavelengths of $\lambda_{b}=\left(v_{b} / v_{f}\right)^{2 / 3} \lambda_{f}$, where $v_{b}$ is the viscosity of the brine, and $v_{f}$ is the viscosity of freshwater (Grazer 1982, Southard and Boguchwal 1990a). For a brine with viscosity 40 times that of pure water, the ripples should be larger than equivalent ripples formed in freshwater by a factor of about 12 , with predicted ripple heights of $18 \mathrm{~cm}$ and wavelengths of $1.08 \mathrm{~m}$ ! When comparing ripple sizes for freshwater flows on Earth to viscous brines on Mars, there is also a dependence on the relative difference in gravitational acceleration to the one-third power (or a length-scale factor of $\sim 1.3$ ) (Southard and Boguchwal 1990b), which is minor given the potential viscosity scale effects considered here. Note that despite their large size, these bed forms would still be considered ripples and not dunes because they formed in the presence of a viscous sublayer (e.g., Garcia 2007).

Finding large current ripples in the Martian sedimentary record would be conclusive evidence for flows with viscosity much greater than that of pure water (the small ripples recorded in Burns formation strata are consistent with, but do not prove, this point, as discussed later herein). First, however, it would need to be established that the bed forms in question were not eolian dunes (e.g., due to an absence of translatent cross strata, pin-stripe lamination, massive grainfall deposits, or other contextual evidence; see Grotzinger et al. [2005] for discussion). If the bed forms can be shown to be subaqueous in origin, there remains the problem of subaqueous ripples versus subaqueous dunes. It is clear from observations both in laboratory flumes and in natural flows on Earth that with increasing sediment size as well as increasing flow velocity, ripples give way abruptly to dunes, which are in large measure similar to ripples in their geometry but are typically an order of magnitude larger in deep freshwater flows (e.g., Southard 1991, Garcia 2007). If we found dune-scale bedforms from liquid flows on Mars, how could we be sure that we were dealing with current ripples (larger by virtue of the greater kinematic viscosities) rather than dunes generated by aqueous flows with viscosities not much greater than that of pure water?

There is a definite minimum dimensionless sediment size for the existence of dunes, and likewise there is a definite maximum sediment size for the existence of ripples (Fig. 7). These scale breaks follow theoretical considerations for the existence of a laminar sublayer, which separates ripples from dunes (Garcia 2007). Three cases can be recognized: (1) the sediment size in the Martian bedforms is sufficiently fine as to be smaller than the minimum sediment size for the existence of subaqueous dunes (i.e., $D<1 \mathrm{~mm}$ in Fig. 7); (2) the sediment size in the Martian bedforms is sufficiently large as to be larger than the maximum sediment size for the existence of subaqueous ripples (i.e., $D>20 \mathrm{~mm}$ in Fig. 7); and (3) the sediment size of the Martian bedforms falls between the sizes noted in cases 1 and 2. It is only in case 3 (i.e., $2<D<20 \mathrm{~mm}$ ) that we cannot be certain whether we are observing either ripples or dunes.

Owing to the relatively fine particle sizes found in crossstratification in the Burns formation $(0.3-0.8 \mathrm{~mm}$; Grotzinger et al. 2005), it is likely that these bed forms are indeed ripples and not dunes. If in fact they were formed by the highly viscous end-member brine modeled by Tosca et al. (2011), we might expect ripple heights of tens of centimeters, whilst observations indicate centimeter-scale crossstratification. Although preservation of full ripple heights in crossstratification requires a high angle of climb (Rubin and Hunter 1982), it seems highly unlikely that the ripples were decimeters high, given the observed centimeter-scale widths of trough cross-beds.

An important caveat to the ripple-size scaling discussed here is that the flows must have had sufficient depth and duration for the ripples to reach their equilibrium form. In the experiments of Coleman and Eling (2000), for example, ripple heights under viscous laminar flows were only $\sim 0.5$ to $1 \mathrm{~cm}$, whereas we might have predicted that their heights should have been tens of centimeters. However, these experiments were only run for 30 to 90 minutes, a duration that was probably not long 
enough for the ripples to reach their equilibrium sizes (Coleman and Eling 2000). Moreover, ripple heights are significantly limited when they reach one-third to one-half the flow depth (e.g., Garcia 2007). In the experiments of Coleman and Eling (2000), flow depths ranged from 3 to $6 \mathrm{~cm}$, which would preclude ripple heights larger than $\sim 1$ to $3 \mathrm{~cm}$.

A reanalysis of the experiments of Grazer (1982) shows similar results. Using only the viscosity scale factor discussed previously, and assuming $\eta_{\mathrm{f}}=1.5 \mathrm{~cm}$ and $\lambda_{\mathrm{f}}=9 \mathrm{~cm}$, we calculated predicted ripple heights and wavelengths for the higher-viscosity fluids used in the experiments and compared these to the measurements of Grazer. The results show that measured ripple heights were much smaller than the predicted values (Fig. 9A). These experiments were run for 25 to 30 hours to ensure that the timescale needed to generate equilibrium ripples was not the limiting factor (Grazer 1982). Indeed, the predictions for larger ripple wavelength with increasing viscosity match the measurements well (Fig. 9B). Thus, it appears that the anomalously small ripple heights are a result of a flow-depth limitation. The predictions match the observations much better when the flow depth is at least twice the predicted ripple height (Fig. 9C). Because the predicted flow depths necessary to generate ripples on Mars by flowing brines might be as low as $1 \mathrm{~cm}$ (Fig. 8), ripple heights could necessarily be small regardless of flow viscosity. Thus, like dunes in freshwater flows, ripples formed by Martian brines may in cases be depth limited; these bed forms are still ripples, however, due to the presence of a viscous sublayer (i.e., small $\mathrm{Re}_{\mathrm{p}}$ ).

\section{IMPLICATIONS FOR BRINES ON MARS}

The analysis here indicates that ripples could be formed from even the most viscous brine modeled by Tosca et al. (2011) under a wide range of sediment sizes, and that the ripples themselves could have heights ranging from a few to tens of centimeters, depending on the flow depth. This notwithstanding, it is very possible that brines might have existed on the Martian surface with substantially lower viscosities than the end-member case considered here. Although the end-member sulfate-dominated case, "brine 6b" of Tosca et al. (2011), is predicted to have a viscosity nearly 40 times that of freshwater at $0^{\circ} \mathrm{C}$, its viscosity is significantly less at warmer temperatures (e.g., $1.6 \times 10^{-5}$ $\mathrm{m}^{2} / \mathrm{s}$ at $25^{\circ} \mathrm{C}$ or 16 times that of freshwater). Composition also influences viscosity. For example, "brine 5b" of Tosca et al. (2011), which is far less acidic than brine $6 \mathrm{~b}$, has a viscosity at equilibrium of $1.1 \times 10^{-5} \mathrm{~m}^{2} / \mathrm{s}$ at $0^{\circ} \mathrm{C}$ and $5.3 \times 10^{-6} \mathrm{~m}^{2} / \mathrm{s}$ at $25^{\circ} \mathrm{C}$ (i.e., 11 -fold and 6 -fold that of freshwater). For these lower-viscosity brines, the ripple stability field in Figure 7 would not extend as far into the coarse sediment sizes, and the predicted equilibrium ripple heights would be substantially less than those discussed previously herein.

The Burns formation at Meridiani Planum presents a case study in ancient subaqueous and eolian sediment transport on the Late Noachian surface of Mars. The evidence for subaqueous sediment transport is very limited, consisting only of thin, decimeter-thick beds of centimeter-scale trough cross-stratification that signify likely brief, shallow, low-discharge overland flows. Evidence for longer-term discharge or more vigorous flows has not been observed, nor has any facies indicative of standing bodies of water such as playas or other lacustrine environments. More recent sedimentological work (Hayes et al. 2011, Edgar et al. this volume) reinforces initial hypotheses formulated at early stages in the mission (Grotzinger et al. 2005, 2006; McLennan et al. 2005) that the Burns formation accumulated in an environment that was generally dry, and only rarely inundated by gentle flows of what must have been very high-concentration brines. This is consistent with our calculations that ripples could be generated by highly viscous brines under only modest flow conditions. For example, with a bed slope of $10^{-3}$, a centimeter-scale-deep laminar flow with velocities of $\sim 0.1 \mathrm{~m} / \mathrm{s}$ would be capable of generating ripples in $1 \mathrm{~mm}$ sand (Fig. 8). Such a flow environment could have
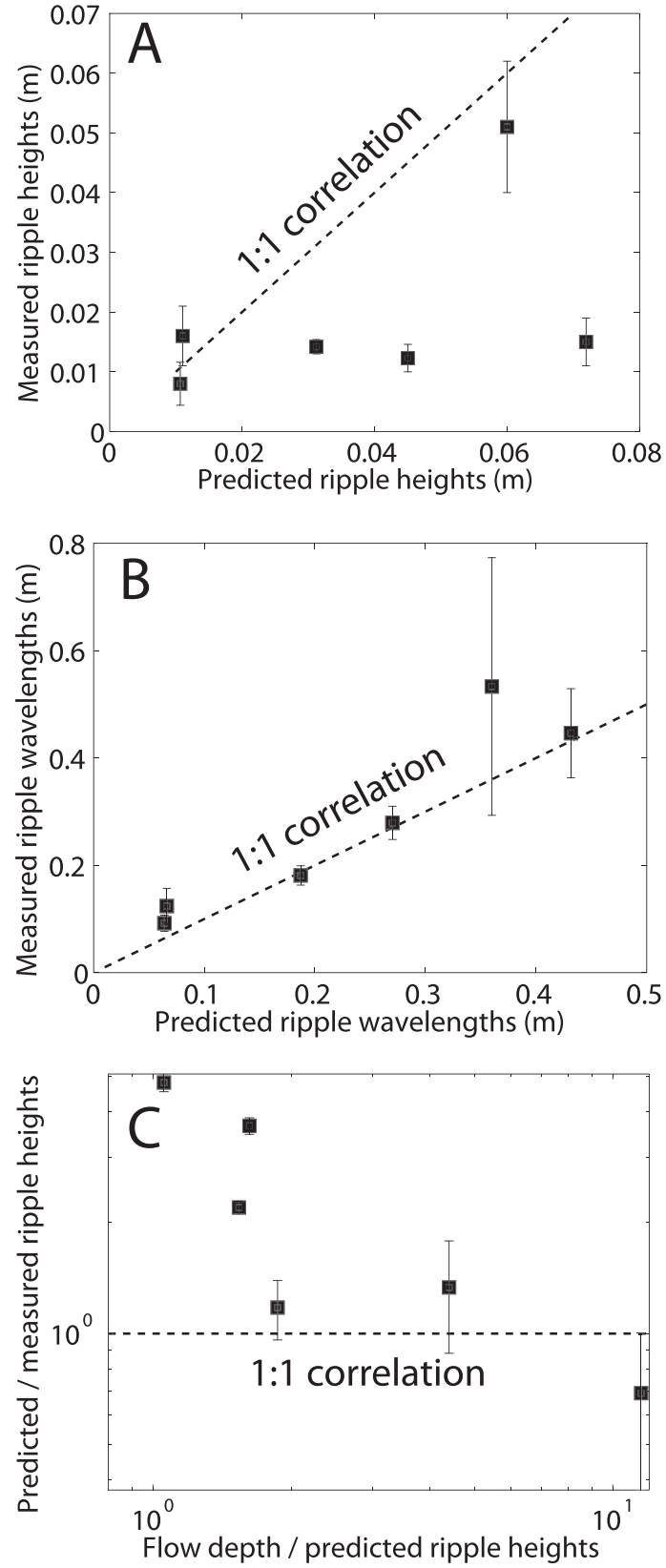

FIG. 9.-Predicted versus measured A) ripple heights and B) wavelengths. Data points are the average ripple dimensions reported by Grazer (1982), and the error bars represent \pm one standard deviation. Ripple dimensions were predicted by assuming freshwater ripple heights of $1.5 \mathrm{~cm}$ and freshwater ripple wavelengths of $9 \mathrm{~cm}$, and adjusting these values only by multiplying by the fluid viscosity scale factor (i.e., relative fluid viscosity raised to the two-thirds power). C) Predicted versus measured ripple heights from part A versus the measured flow depth normalized by the predicted ripple height. All dashed lines represent a perfect match between prediction and measurement. 


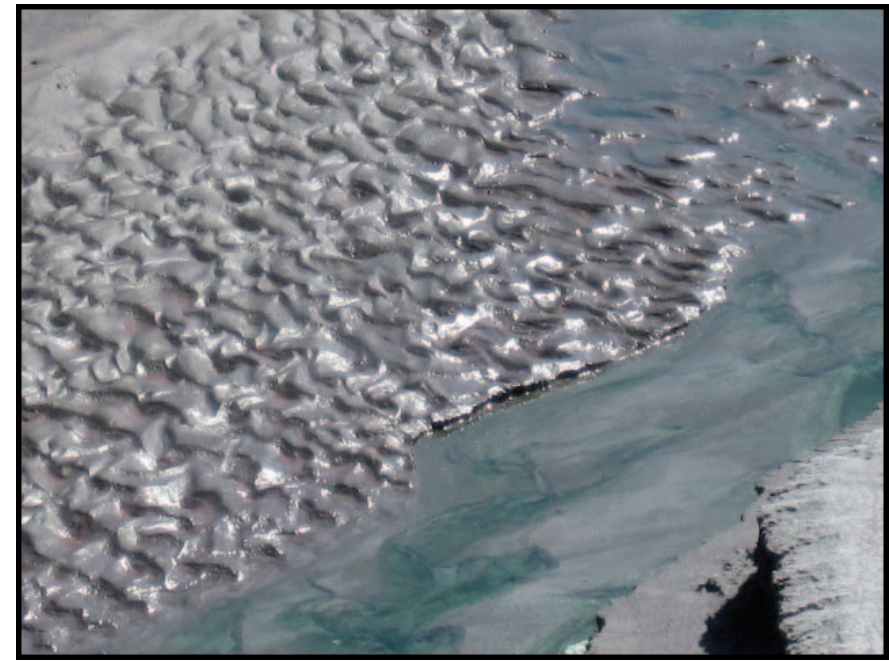

FIG. 10.-Centimeter-scale ripples developed in a shallow flow that emerges from a large pile of sulfide-rich mine tailings at Rio Tinto, Spain. The groundwater is very acidic $(\mathrm{pH} \mathrm{1-2)}$ and sulfate rich, and it emerges in small channels that collect to form larger channels such as the one shown here. Ripples are formed of sand-size particles that are aggregates of weathered silicate minerals, plus Ca$\mathrm{Mg}-\mathrm{Fe}-\mathrm{Al}$ sulfate minerals. This is almost identical to what is inferred for the composition of sand particles that compose the Burns formation (Clark et al. 2005, McLennan et al. 2005). The brines are close chemical analogs as well, with high concentrations of $\mathrm{Fe}^{2+}, \mathrm{Mg}$, and $\mathrm{Al}$, but they are toward the dilute end of those calculated in Tosca et al. (2011) for Mars. The ripples have threedimensional crest lines and well-developed scour pits that will create centimeter-scale cross-lamination during migration. Flow is from right to left, and the fully submerged channel in the foreground is about $0.75 \mathrm{~m}$ in width.

been created by one interdune depression filling with brine relative to an adjacent, lower depression, allowing the brine to move from the former to the latter. If the filling events were brief enough, sediment could be transported without the creation of a lacustrine facies per se.

Farther afield, substantial sulfate deposits are observed elsewhere on Mars, such as the Vallis Marineris and adjacent chasmata (Bibring et al. 2005, Murchie et al. 2009). Sulfates are also being discovered in other types of topographic depressions, such as large craters (Milliken et al. 2010). Most recently, sulfates are being seen as an important component of the oldest terrains on Mars (e.g. Nili Fossae, NE Syrtis [Ehlmann et al. 2009]; Mawrth Vallis [Wray et al. 2010]). Given that these sulfate minerals are hydrated, it is reasonable to assume that sediment transport at these sites may have-at least in part-been driven by subaqueous sediment transport. It is also possible that in some cases, these sequences were subjected to even greater volumes of flowing water than what is inferred for the ancient record at Meridiani. If so, then this also would have required the fluid to be a brine of high concentration since epsomite is inferred to be one of the most common minerals (Bibring et al. 2005, Murchie et al. 2009).

This leads to at least two possible scenarios for the creation of such a brine, and the way in which it could have led to deposition of sulfaterich sediments. In the first case, dissolution of basalt under acidic conditions may have led to the creation of sulfate-rich pore fluids (Tosca et al. 2005) that discharged as briny groundwater in topographic depressions, perhaps along the lines of what has been suggested for
Meridiani (Andrews-Hanna et al. 2007). Evaporation of the brine might have produced a series of evaporitic playas; flow between basins might have induced ripples and other sedimentary bed forms to form. In the second scenario, the sulfate-rich deposits were generated via some other mechanism, such as hydrothermal alteration. The deposits then interacted with freshwater, so that the deposit was leached and/or eroded in the topographically updip portions of the aquifer as the freshwater reached saturation with respect to the sulfate mineral phases. Farther downdip, the sulfate deposit would exist in equilibrium with the fluid, experiencing no net gain or loss of sulfate from solution. In the most downdip positions, the fluid may have emerged, creating surface flows of highly concentrated brines. A similar process occurs today at Rio Tinto, Spain, where emerging sulfate-rich groundwater precipitates to create sediment particles that are then transported by the flow to form centimeter-scale ripples (Fig. 10). These ripples are possible analogs for those inferred to have formed in the Burns formation.

\section{CONCLUSIONS}

Cross-stratification preserved in the Burns formation suggests formation by flowing aqueous fluids. Given the extremely high solubility of the minerals observed there, it seems likely that these flows must have been brines of high ionic strength, which necessarily have densities and viscosities that exceed that of freshwater. A compilation of previous studies on bed form stability and ripple formation under high-viscosity fluids indicates that ripples generated by flowing viscous brines on Mars would be stable over a wide range of bed shear stresses and particle sizes, including sand and gravel; i.e., sizes much larger than the stability limit for ripples in freshwater on Earth. It is likely that ripples might also form in silt sizes under viscous brines, but these conditions (i.e., particle Reynolds numbers less than 0.1 ) have not yet been explored in flume experiments, motivating future work. To generate the necessary bed stresses, the brines must have had flow depths ranging from 0.01 to $1 \mathrm{~m}$ and flow velocities of 0.01 to $1 \mathrm{~m} / \mathrm{s}$, and been driven by gravity on slopes of $10^{-4}$ to $10^{-2}$. These conditions seem reasonable given the interdune environment proposed for the Burns formation. Ripples formed by viscous brines might be larger than their freshwater counterparts, potentially by as much as a factor of twelve for the highest viscosity case considered. Thus, large $(>10 \mathrm{~cm})$, fine-grained $(<1 \mathrm{~mm})$ cross strata of subaqueous origin would be compelling physical evidence for flowing brines in the Martian past. This notwithstanding, smaller ripples might also be produced by flowing brines if ripple growth was limited by the flow depth, or if equilibrium brine viscosity was not as high as the endmember brine considered. For these cases, the physical sedimentological evidence in support of brines versus freshwater flows may be ambiguous. Reconstruction of small ripples in the Burns formation supports these inferences.

\section{ACKNOWLEDGMENTS}

We thank two reviewers whose comments added clarity to the final manuscript and Ralph Milliken for serving as editor. J.P.G. acknowledges support from the NASA Astrobiology Institute and the Mars Exploration Rover Project. M.P.L. acknowledges the Donors of the American Chemical Society Petroleum Research Fund for partial support of this research.

\section{REFERENCES}

Alkattan M. 1997. Experimental studies of halite dissolution kinetics: 1. The effect of saturation state and the presence of trace metals. Chemical Geology 137(3-4):201-219.

Andrews-Hanna JC, Philips RJ, Zuber MT. 2007. Meridiani Planum and the global hydrology of Mars. Nature 443:163-166. 
Baas JH. 1999. An empirical model for the development and equilibrium morphology of current ripples in fine sand. Sedimentology 46:123-138.

Benison KC, LaClair D, Walker J. 2008. Physical sedimentology experiments with sulfuric acid solutions: Implications for Mars?: Earth and Planetary Science Letters 270:330-337.

Best JL, Leeder M. 1993. Drag reduction in turbulent muddy seawater flows and some sedimentary consequences. Sedimentology 40:1129-1137.

Betat A, Kruelle CA, Frette V, Rehberg I. 2002. Long-time behavior of sand ripples induced by water shear flow. European Physical Journal E 8:465-476.

Bibring J-P, Langevin Y, Gendrin A, Gondet B, Poulet F, Berthe M, Soufflot A, Arvidson R, Mangold N, Mustard J, Drossart P, Team ATO. 2005. Mars surface diversity as revealed by the OMEGA/Mars Express observations Science 307:1576-1581.

Boguchwal LA, Southard JB. 1990. Bed configurations in steady unidirectional water flows: 1. Scale-model study using fine sands. Journal of Sedimentary Petrology 60:649-657.

Brownlie WR. 1983. Flow depth in sand-bed channels. Journal of Hydraulic Engineering 109:959-990.

Chabert J, Chauvin JL. 1963. Formation de dunes et de rides dans les modeles fluviaux. Bulletin du Centre de Recherche et d'Essais de Chatou 4:31-51.

Chow VT. 1959. Open Channel Hydraulics: McGraw Hill, New York. 680 p.

Clark BC, Morris RV, McLennan SM, Gellert R, Jolliff B, Knoll AH, Squyres SW, Lowenstein TK, Ming DW, Tosca NJ, Yen A, Christensen PR, Gorevan S, Bruckner J, Calvin W, Dreibus G, Farrand W, Klingelhoefer G, Waenke H, Zipfel J, Bell J.F, Grotzinger J, McSween HY, Rieder R. 2005. Chemistry and mineralogy of outcrops at Meridiani Planum. Earth and Planetary Science Letters 240:73-94.

Coleman SE, Eling B. 2000. Sand wavelets in laminar open-channel flows. Journal of Hydraulic Research 38:331-338.

Devauchelle O, Malverti L, Lajeunesse E, Lagree PY, Josserand C, Thu-Lam KDN. 2010. Stability of bedforms in laminar flows with free surface: From bars to ripples. Journal of Fluid Mechanics 642:329-348.

Dzulynski S, Sanders JE. 1962. Current marks on frim mud bottoms: Transactions of the Connecticut Academy of Arts and Sciences 42:57-96.

Ehlmann BL, Mustard JF, Swayze GA, Clark RN, Bishop JL, Poulet F, Des Marais D, Roach LH, Milliken RE, Wray J, Barnouin-Jha O, Murchie SL. 2009. Identification of hydrated silicate minerals on Mars using MROCRISM: Geologic context near Nili Fossae and implications for aqueous alteration. Journal of Geophsical Research 114, doi:10.1029/2009JE003339.

Garcia MH. 2007. Sedimentation Engineering: Process, Measurement, Modeling, and Practice: American Society of Civil Engineers, Reston, Virginia, $1132 \mathrm{p}$.

Grazer RA. 1982. Experimental study of current ripples using medium silt [unpublished MS thesis]: Massechusetts Institute of Technology, Cambridge, Massachusetts, $131 \mathrm{p}$.

Grotzinger JP, Arvidson RE, Bell JF, Calvin W, Clark BC, Fike DA, Golombek M, Greeley R, Haldemann A, Herkenhoff KE, Jolliff BL, Knoll AH, Malin M, McLennan SM, Parker T, Soderblom L, Sohl-Dickstein JN, Squyres SW, Tosca NJ, Watters WA. 2005. Stratigraphy and sedimentology of a dry to wet aeolian depositional system, Burns formation, Meridiani Planum, Mars. Earth and Planetary Science Letters 240:11-72.

Grotzinger JP, Bell J, Herkenhoff K, Johnson J, Knoll A, McCartney E, McLennan S, Metz J, Moore J, Squyres S, Sullivan R, Aharonson A, Arvidson R, Joliff B, Golombek M, Lewis K, Parker T, Soderblom J. 2006. Sedimentary textures formed by aqueous processes, Erebus crater, Meridiani Planum, Mars. Geology 34:1085-1088.

Hayes AG, Grotzinger JP, Edgar LA, Squyres SW, Watters WA, Sohl-Dickstein J, Athena Science Team. 2011. Reconstruction of eolian beforms and paleocurrents from cross-bedded strata at Victoria crater, Meridiani Planum, Mars. Journal of Geophysical Research 116, doi:10.1029/2010JE003688.

Kerr RC. 1995. Convective crystal dissolution. Contributions to Mineralogy and Petrology 121:237-246.

Komar PD. 1979. Comparisons of the hydraulics of water flows in Martian outflow chanels with flows of similar scale on Earth. Icarus 37:156-181.

Lajeunesse E, Malverti L, Lancien P, Armstrong L, Metivier F, Coleman S, Smith CE, Davies T, Cantelli A, Parker G. 2010. Fluvial and submarine morphodynamics of laminar and near-laminar flows: A synthesis. Sedimentology 57:1-26.
Lasaga AC. 1998. Kinetic Theory in the Earth Sciences: Princeton University Press, Princeton, New Jersey, $811 \mathrm{p}$.

McLennan SM, Bell JF, Calvin WM, Christensen PR, Clark BC, de Souza PA, Farmer J, Farrand WH, Fike DA, Gellert R, Ghosh A, Glotch TD, Grotzinger JP, Hahn B, Herkenhoff KE, Hurowitz JA, Johnson JR, Johnson SS, Jolliff B, Klingelhofer G, Knoll AH, Learner Z, Malin MC, McSween HY, Pocock J, Ruff SW, Soderblom LA, Squyres SW, Tosca NJ, Watters WA, Wyatt MB, Yen A. 2005. Provenance and diagenesis of the evaporite-bearing Burns formation, Meridiani Planum, Mars. Earth and Planetary Science Letters 240:95-121.

McLennan SM, Grotzinger JP. 2008. The sedimentary rock cycle of Mars. In Bell, J (Editor), The Martian Surface: Composition, Mineralogy, and Physical Properties. Cambridge University Press, Cambridge, UK. p. 541577.

Mehta AJ. 1991. Understanding fluid mud in a dynamic environment. GeoMarine Letters 11:113-118.

Metz JM, Grotzinger JP, Rubin DM, Lewis KW, Squyres SW, Bell JF. 2009. Sulfate-rich eolian and wet interdune deposits, Erebus crater, Meridiani Planum, Mars. Journal of Sedimentary Research 79:247-264.

Milliken RE, Grotzinger JP, Thomson BJ. 2010. Paleoclimate of Mars as captured by the stratigraphic record of Gale crater. Geophysical Research Letters 37, doi:10.1029/2009GL041870.

Murchie SL, Mustard JF, Ehlmann BL, Milliken RE, Bishop JL, McKeown NK, Dobrea EZN, Seelos FP, Buczkowski DL, Wiseman SM, Arvidson RE, Wray JJ, Swayze G, Clark RN, Marais DJD, McEwen AS, Bibring J.-P. 2009. A synthesis of Martian aqueous mineralogy after 1 Mars year of observations from the Mars Reconnaissance Orbiter. Journal of Geophysical Research 114, doi: 10.1029/2009JE003342

Parker G. 1991. Selective sorting and abrasion of river gravel. II: Applications. Journal of Hydraulic Engineering 117:150-171.

Rubin DM. 1987. Cross-Bedding, Bedforms, and Paleocurrents: Society for Sedimentary Geology, Tulsa, Oklahoma. SEPM, Concepts in Sedimentology and Paleontology 1, $187 \mathrm{p}$.

Rubin DM, Hunter RE. 1982. Bedform climbing in theory and nature Sedimentology 29:121-138.

Shields A. 1936. Application of Similarity Principles and Turbulence Research to Bed-Load Movement: California Institute of Technology, U.S. Dept of Agriculture Soil Conservation Service Cooperative Laboratory, Pasadena, California. Hydrodynamics Laboratory Publication 167, 47 p.

Simon B. 1981. Dissolution rates of $\mathrm{NaCl}$ and $\mathrm{KCl}$ in aqueous solutions. Journal of Crystal Growth 52:789-794.

Southard JB. 1991. Experimental determination of bed-form stability. Annual Review of Earth and Planetary Sciences 19:423-455.

Southard JB, Boguchwal LA. 1973. Flume experiments on the transition from ripples to lower flat bed with increasing sand size. Journal of Sedimentary Research 43:1114-1121.

Southard JB, Boguchwal LA. 1990a. Bed configurations in steady unidirectional water flows: 2. Synthesis of flume data. Journal of Sedimentary Petrology 60:658-679.

Southard JB, Boguchwal LA. 1990b. Bed configurations in steady unidirectional water flows: 3. Effects of temperature and gravity. Journal of Sedimentary Petrology 60:680-686.

Squyres SW, Grotzinger JP, Arvidson RE, Bell JF, Calvin W, Christensen PR, Clark BC, Crisp JA, Farrand WH, Herkenhoff KE, Johnson JR, Klingelhofer G, Knoll AH, McLennan SM, McSween HY, Morris RV, Rice JW, Rieder R, Soderblom LA. 2004. In situ evidence for an ancient aqueous environment at Meridiani Planum, Mars. Science 306:1709-1714.

Squyres SW, Knoll AH, Arvidson RE, Ashley JW, Bell JF III, Calvin WM, Christensen PR, Clark BC, Cohen BA, de Souza PA Jr, Edgar L, Farrand WH, Fleischer I, Gellert R, Golombek MP, Grant J, Grotzinger J, Hayes A, Herkenhoff KE, Johnson JR, Jolliff B, Klingelhöfer G, Knudson A, Li R, McCoy TJ, McLennan SM, Ming DW, Mittlefehldt DW, Morris RV, Rice JW Jr, Schröder C, Sullivan RJ, Yen A, Yingst RA. 2009. Exploration of Victoria Crater by the rover Opportunity. Science 324, doi: 10.1126/science.1170355.

Tosca NJ, McLennan SM, Clark BC, Grotzinger JP, Hurowitz JA, Knoll AH, Schroder C, Squyres SW. 2005. Geochemical modeling of evaporation processes on Mars: Insight from the sedimentary record at Meridiani Planum. Earth and Planetary Science Letters 240:122-148. 
Tosca NJ, McLennan SM, Lamb MP, Grotzinger JP. 2011. Physico-chemical properties of concentrated Martian surface waters. Journal of Geophysical Research—Planets 116, doi:10.1029/2010JE003700.

van den Berg JH, van Gelder A. 1993. A new bedform stability diagram, with emphasis on the transition of ripples to plane bed in flows over fine sand and silt. In Marzo M, Puigdefábregas C (Editors), Alluvial Sedimentation: International Association of Sedimentologists, Special Publication 17, Blackwell Scientific Publications, Oxford, UK. p. 11-21.

Vanoni VA. 1974. Factors determining bed form of alluvial streams. Journal of the Hydraulics Division 100:363-378.

Van Rijn LC. 1984. Sediment transport: Part III. Bed forms and alluvial roughness. Journal of Hydraulic Engineering 110:1613-1641.

Velbel MA. 2004. Laboratory and homework exercises in the geochemical kinetics of mineral-water reaction: Rate law, Arrhenius activation energy, and the rate-determining step in the dissolution of halite. Journal of Geological Education 52:52-59.

White SJ. 1970. Plane bed thresholds of fine grained sediments. Nature 228:152-153.

Wray JJ, Squyres SW, Roach LH, Bishop JL, Mustard JF, Noe Dobrea EZ. 2010. Identification of the Ca-sulfate bassanite in Mawrth Vallis, Mars. Icarus 209:416-421, doi:10.1016/j.icarus.2010.06.001.

Yalin MS. 1977. Mechanics of Sediment Transport: Pergamon Press, Oxford, UK. 298 p. 